\title{
Emergent Bilingualism and Working Memory Development in School Aged
}

\section{Children}

Laura Birke Hansen ${ }^{\mathrm{a}}$, Pedro Macizo ${ }^{\mathrm{a}}$, Jon Andoni Duñabeitia ${ }^{\mathrm{b}}$, David Saldaña ${ }^{\mathrm{c}}$, Manuel Carreiras $^{\text {b, d, e }}$, Luis J. Fuentes ${ }^{\mathrm{f}}$, \& M. Teresa Bajo ${ }^{\mathrm{a}}$

${ }^{a}$ Centro de Investigación Mente, Cerebro y Comportamiento (CIMCYC), Universidad de Granada, Campus Universitario de Cartuja s/n, 18071, Granada, Spain.

${ }^{\mathrm{b}}$ Basque Center on Cognition, Brain and Language (BCBL), Paseo Miketelegi, 20009, San Sebastian - Donostia, Guipúzcoa, Spain.

${ }^{\mathrm{c}}$ Universidad de Sevilla, Calle San Fernando, 4, 41004 Sevilla, Spain.

d Ikerbasque, Basque Foundation for Science, María Diaz de Haro 3, 48013 Bilbao, Biskaia, Spain.

e Universidad del País Vasco, 48940 Bilbao, Biskaia, Spain.

${ }^{\mathrm{f}}$ Universidad de Murcia, Campus Universitario de Espinardo s/n; 30100, Espinardo, Murcia, Spain.

Corresponding author:

Laura Birke Hansen

E-mail: laurabirke@ugr.es, phone: +34-622123679

Word count: 8494; Figures: 3; Tables: 2.

Key words: Emergent Bilingualism, Immersion Schooling, Working Memory, Executive Updating, Verbal Processing 
Author note

This research was partially supported by doctoral research grant AP2010-3434 from the Spanish Ministry of Education to Laura Birke Hansen, grant CSD2008-00048 to all authors, grant PSI2012-32287 from the Spanish Ministry of Economy and Competitiveness to Pedro Macizo, grant PSI2012-33625 from the Spanish Ministry of Education, and grants CTS 2369 from the Andalusian Government, and APCIN. NSFPIRE to M. Teresa Bajo. We are thankful to all children, their parents and schools for their participation in this project. 


\begin{abstract}
The present research explores working memory (WM) development in monolingual as well as emergent bilingual children immersed in an L2 at school. Evidence from recent years suggests that bilingualism may boost domain-general executive control, but impair non-executive linguistic processing. Both are relevant for verbal WM, but different paradigms currently in use vary in the degree to which they reflect these subprocesses. We found that only younger immersion students outperformed monolinguals on the n-back task, a measure of executive WM updating, but showed a relative deficit in L1 rapid naming, and to a lesser degree, reading span scores. Age effects suggest that rather than ultimate performance levels, bilingualism alters the developmental course of WMprocesses. We conclude that emergent bilingualism may modulate WM development in school-aged children at the sub-component level, but detecting this modulation is contingent on task selection.
\end{abstract}

Key words: Emergent Bilingualism, Immersion Schooling, Working Memory, Executive Updating, Verbal Processing 
Bilingualism is among the factors that can affect cognitive development, slowing or accelerating the acquisition and maturation of particular cognitive skills. While certain lags or deficits have been observed in the realm of language development and linguistic processing, the development of executive functions may benefit from multiple language competence and use (for a review, see Bialystok, 2009). Until recently, research on the cognitive consequences of bilingualism had been based almost exclusively on highly proficient and relatively balanced bilinguals who had acquired both languages early in life (before starting school) at home or in the community (see Adesope, Lavin, Thompson \& Ungerleider, 2010, Bialystok, 2009, Hilchey \& Klein, 2011). Recent research, however, suggests that if the immersion duration has been sufficient, the beneficial effect bilingualism has on executive control may extend to second language learners attending bilingual immersion schools (Nicolay \& Poncelet, 2013, 2015). Immersion schooling, where the foreign language is not just the subject, but the medium of instruction, provides children from monolingual homes and communities with the opportunity for a bilingual education and is thus becoming increasingly popular. In what way this "path" to bilingualism affects the development of cognitive skills and abilities is therefore of critical importance. Here we aim to explore the development of working memory (WM) through school age in monolingual children and children who are in the process of becoming bilingual via attendance of an immersion school.

WM is key to the development of complex cognitive skills such as mathematics (Raghubar, Barnes \& Hecht, 2010) and reading comprehension (Carretti, Borella, Cornoldi \& de Beni, 2009), and is a predictor for academic attainment (Gathercole, Pickering, Knight \& Stegmann, 2004). It is thus unsurprising that researchers have started to explore the consequences of bilingualism on WM development (e.g., Engel de 
Abreu, 2011, Morales, Calvo \& Bialystok, 2013, Namazi \& Thorardottir, 2010).

However, to our knowledge, the existing research has not been extended to second language learners undergoing bilingual immersion.

The notion of a "bilingual cognitive advantage" arises from cumulated evidence that bilinguals excel on tasks that rely heavily on executive control (e. g., Adesope et al., 2010, Bialystok, 2001, Bialystok, 2009). It has been suggested that the origin of this phenomenon lies in the parallel language activation that arises during bilingual speech production and comprehension (e.g., Thierry \& Wu, 2007, Van Hell \& Dijkstra, 2002) resulting in between-language interference which requires resolution. Controlled attention for bilingual language processing has been shown to be mediated at least partially by domain-general executive control mechanisms (for a meta-analysis, see Luk, Green, Abutalebi \& Grady, 2012), and the constant recruitment of these mechanisms during bilinguals' standard, everyday language processing is thought to render bilingualism a type of lifelong cognitive training that generalizes to executive processes beyond the linguistic domain (e. g. Bialystok, 2001). More recently, some authors have reported failures to replicate bilingual advantages in executive control (Antón et al., 2014, Duñabeitia et al., 2014, Namazi \& Thorardottir, 2010, Paap \& Greenberg, 2013), suggesting that perhaps this universal account lacks precision, and that the outcome of the between-group comparisons may depend on additional factors such as task-specific demands, bilingual population, or executive process in question.

In terms of specific target executive functions and mediating processes, the overall pattern of results is somewhat difficult to interpret because, for one, no single valid model of executive functions exists. A popular account that has often been referred to in the bilingual advantage literature identifies shifting or switching attention between 
tasks or mental sets (“Shifting”), updating and monitoring of representations in WM ("Updating"), and controlled inhibition of prepotent responses ("Inhibition") as distinguishable, key mechanisms of executive control (Miyake, Friedman, Emerson, Witzki \& Howerter, 2000). The components work in inseparable unison during task performance. From this theoretical perspective, WM is closely related to executive functioning, especially its updating component, as it refers to the online storage and manipulation of information (Baddeley \& Hitch 1974) and provides the capacity for the maintenance of goal-related information necessary to coordinate task-relevant processes (Miyake et al.,, 2000). The conceptual overlap between WM and executive control is corroborated empirically by virtue of a close reciprocal relationship between measures of WM and executive control (McCabe, Roediger, McDaniel, Balota \& Hambrick, 2010).

However, WM entails both executive and nonexecutive components or subprocesses (Baddeley \& Hitch, 1974, Gathercole, Pickering, Ambridge \& Wearing, 2004). Measures of WM differ in the relative degree to which they draw on domain-general executive control or domain-specific verbal or visuo-spatial storage. To assess WM performance, many researchers refer to either complex span procedures like reading span or operational span (Daneman \& Carpenter, 1980), which combine recall with a secondary task, or versions of the n-back task (Cohen et al., 1997), where participants are required to evaluate sequentially presented stimuli for a match at a given lag (1back, 2-back or 3-back). Both families of tasks tap into the updating and monitoring aspect of WM (Schmiedek, Hildebrandt, Lövdén, Wilhelm \& Lindenberger, 2009). However, while complex span paradigms provide a more balanced measure of executive processing and short-term storage capacity (e.g., Bayliss, Jarrold, Gunn \& Baddeley, 2003), the n-back task is thought to mainly reflect the updating component of executive 
functioning (Cohen et al., 1997, Miyake et al., 2000).

Beyond task-specific demands, separate WM components show independent developmental curves in school-aged children (Gathercole et al., 2004) and may be modulated differentially by developmental factors like bilingualism. This is crucial when exploring bilingual effects on WM because developmental bilingualism may come with costs in the linguistic domain. For example, monolinguals tend to score higher on tests of receptive or productive vocabulary than age-matched bilingual toddlers (Poulin-Dubois, Bialystok, Blaye, Polonia \& Yott, 2012), preschool and schoolaged children (e.g., Bialystok, Luk, Peets \& Yang, 2010), and adults (e.g., Bialystok \& Luk, 2012), and bilingual children and adults show more difficulties and slower reaction times in lexical access and lexical retrieval (e.g., Ivanova \& Costa, 2008, Yan \& Nicoladis, 2009). Importantly, this phenomenon extends to bilinguals' L1 and can be observed in sequential bilinguals after being immersed in a weaker L2 (Linck, Kroll, \& Sunderman, 2009). Thus, while domain-general executive processes operating on WM may benefit from a general executive advantage, domain-specific verbal storage may be negatively affected by linguistic costs (Luo, Craik, Moreno \& Bialystok, 2012). In sum, WM performance in bilinguals may be influenced by two counteracting effects that cancel each other out, ultimately placing bilinguals at the same overall level as their monolingual peers (Bialystok \& Feng, 2009).

Existing research into bilinguals' WM performance reflects this ambiguity. Generally speaking, superior bilingual-to-monolingual performance tends to be observed when the relative executive demand is high. For example, on a variation of the Simon task that combined varying demands for WM and conflict resolution, five- and seven-year-old bilinguals were better able to handle increased WM load than 
monolinguals of the same age, even in the absence of conflict (Morales et al., 2013). In addition, bilingual participants of both age groups outperformed their monolingual peers on (complex) visual WM span. Regarding verbal updating, Carlson and Meltzoff (2008) reported a bilingual advantage once socioeconomic status and verbal abilities - where bilinguals were at disadvantage - had been statistically controlled for. On the other hand, no differences were observed when comparing bilingual and monolingual preschool children, school-aged children, adolescents or young adults on verbal, visuospatial, or symbolic memory (Bonifacci, Giombini, Bellocchi, \& Contento, 2011, Engel de Abreu, 2011, Namazi \& Thorardottir, 2010). All of the latter studies used simple span procedures, adding only minimal manipulation of the digits retained in WM (e. g., backwards span), and thus relatively minor executive demands (see Engle, Tuholski, Laughlin \& Conway, 1999). This factor, in combination with putative linguistic disadvantages in bilinguals, may account for the mixed pattern of results.

Few studies have tried to extend these findings to second language learners attending bilingual immersion schooling (emergent bilinguals). In fact, the research by Carlson and Meltzoff (2008) has been the only one to assess this particular subgroup on a WM updating task. In terms of other aspects of executive functioning, the limited number of studies that exists seems to suggest that an executive advantage may emerge, but is constrained by how long a child has been immersed in the L2. Thus, compared to age-matched monolingual controls, no between-group differences emerged for children after 6 months (Carlson \& Meltzoff, 2008), or 12 months of bilingual immersion (Poarch \& van Hell, 2012). However, after having undergone bilingual immersion for three years, a group of eight year old emergent bilinguals outperformed their monolingual peers on a range of executive measures (Nicolay \& Poncelet, 2013, for a longitudinal replication, Nicolay \& Poncelet, 2015). In line with this gradient, within a 
group of children attending the same bilingual immersion school, a reduction in interference cost was related to balanced proficiency and length of time the child had been enrolled in the school (Bialystok \& Barac, 2012). In sum, according to previous evidence, one might expect emergent bilinguals immersed in an L2 at school to show a relative benefit in WM if i) the task taps into central executive processes and ii) they have been immersed for a minimum duration.

In addition, based on the discussion regarding possible linguistic costs of bilingualism, and the involvement of domain-specific verbal resources in some WM tasks, it is possible that bilingual advantages only emerge if the WM task has relatively low linguistic demands. However, while there is some research extending the patterns of results regarding executive function from early bilinguals to L2 immersion students, there is less evidence as to whether the typical linguistic costs might also extend to this type of bilingualism, in particular, whether any consequences emerge for children's dominant L1. Research with adult sequential bilinguals showing slowed lexical access in the L1 as a consequence of L2 immersion suggests this might be the case (Linck et al., 2009). On the other hand, even with fulltime immersion programs, L2 immersion students typically return to a dominant L1 environment outside of school every day. Overall, it is currently unclear whether linguistic costs for the L1 can be observed in emergent bilingual children in L2 immersion schooling, and whether these costs might extend to verbal WM.

\section{The present research}

The main aim of the present research was to explore the development of WM in school aged children attending bilingual immersion versus monolingual schools in an otherwise monolingual community. Children were tested on two measures of verbal 
WM in their L1, an n-back task with letters, and reading span. Both combine executive and linguistic demands, but differ in the relative degree to which they rely on these subprocesses. Generally speaking, the executive load of the n-back task is higher, especially in regards to updating (i.e., continually monitoring and refreshing items held in WM) and interference control (i.e., managing interference from items that are currently irrelevant, but had been relevant in a preceding trial and may become relevant again). The reading span task places higher demands on linguistic processes, and is affected by factors such as verbal processing speed (Bayliss et al., 2003). In terms of different WM components, reading span is a balanced measure of the domain-general executive central and domain-general verbal storage, while the n-back task mainly reflects central executive processes (Bayliss et al., 2003, Schmiedek et al., 2009). Importantly, these differences are relative: the n-back task also involves processing and storage of verbal information, and the reading span task requires updating and interference control, but to a lesser degree than the respective other task. Our aim in selecting these two tasks was thus to identify and dissociate executive (beneficial) and linguistic (detrimental) consequences of emerging bilingualism for WM performance. Given that it is currently unknown whether the linguistic deficits found in early, balanced bilinguals (e.g. Bialystok, 2001) extend to L1 performance in immersion students, we additionally included two language tasks to measure vocabulary and lexical access. Our predictions were as follows. If L2 immersion students experience the same pattern of linguistic costs and executive benefits that has been reported for early, balanced bilinguals, we would expect monolingual children to score higher than their bilingual peers on measures of vocabulary and lexical access. We might further expect emergent bilinguals to show superior performance on the n-back task, an indicator of executive updating, while reading span, which has higher linguistic demands than the n-back task, might not 
show any between-group discrepancies, because an advantage in executive control might be cancelled out by linguistic processing costs.

Children were attending grade 2, 3, 5 or 8 at the time of testing. These age groups represent critical stages in the developmental trajectory of WM as well as the cumulative experience with bilingualism. Critical developmental stages are achieved with a qualitative shift around the age of seven to eight (grades 2-3) when children start to spontaneously engage in phonological rehearsal (e.g., Gaillard, Barrouillet, Jarrold \& Camos, 2011), and with the beginning of adolescence (around age 11, grade 5), as the components of WM and their coordination begin to function an adult-like fashion (e.g., Gathercole et al., 2004). Further quantitative increases continue until later in adolescence. In addition, children in the second grade have been immersed in their L2 for a year and a half, the duration for which cognitive consequences started to become detectable in previous research (Poarch \& van Hell, 2012). We expected both agerelated and immersion-related changes in WM performance to be more pronounced in younger children, and therefore included consecutive age groups in the lower grades and fewer selected groups of older children.

\section{Method}

\section{Participants}

Participants were 152 children (70 boys and 82 girls) who were recruited as part of a large scale research project cognition and education. At the time of testing, 38 children were attending the second grade, 42 the third grade, 42 the fifth grade and 30 the eighth grade. All participants were native speakers of Spanish, the language of testing; half of them $(n=76)$ were attending a fulltime English immersion program 
(bilinguals), the other half $(n=76)$ a monolingual Spanish school (monolinguals).

There were equal numbers of bilingual and monolingual children within each grade level. Monolingual and bilingual children were matched for age and gender. Students with dyslexia, ADHD or other developmental disorders, and children who had been exposed to a language other than Spanish outside of school were excluded from the sample.

Bilinguals had been immersed in the English language since the beginning of first grade. For this group, all school activities and instructions were in English, except for Spanish language and literature classes, which were taught in Spanish. In the first and second grade, children had 27.5 hours of L2 immersion per week. Third and fourth graders had 26.5 weekly hours of L2 immersion, and in grades 5 through 8, children had 22.5 hours of L2 English immersion. In addition, all children (bilinguals and monolinguals) started foreign language classes in French in grade 5, with 3 hours per week. Classroom instruction and communication in the monolingual program was entirely in Spanish, with the exception of foreign language instruction in English (up until grade 4: 2h/week, starting from grade 5: 3 hours/week) and French. The two groups were compared on a number of background measures (see Table 1 for descriptive statistics).

\section{[Insert Table 1]}

As an index of SES, we obtained questionnaire scores for parents' educational level. A parent's score reflects their highest diploma obtained, distinguishing between graduates of university level (5), vocational training (4), high school (3), secondary/middle school (2) and elementary school (1) institutions. Separate values were obtained for paternal and maternal education and were submitted to $\chi^{2}$ - likelihood 
ratio tests. In addition, we assessed parental investment in home literacy environment (HLE). Questions regarding HLE were included in a family questionnaire (e. g.: "We encourage our child to read."), and four answer categories were provided for each item: Never (0), sometimes (1), almost always (2), and always (3). Sum scores were subjected to two-way factorial ANOVAs with the factors age and language status. Fluid intelligence was measured by means of the K-BIT matrices subscale (Kaufman \& Kaufman, 2000), a paper and pencil test of fluid and crystallized intelligence. We used raw scores to compare performance.

The overall level of socioeconomic status and home literacy environment was high in both groups. $\chi^{2}$-likelihood ratio tests revealed no monolingual-versus-bilingual differences regarding paternal or maternal education, indicating similar SES across the families of bilingual and monolingual children (maternal education level across age groups; $\chi^{2}(4)=1.83, p>.05$, grade $2: \chi^{2}(4)=2.1, p>.05$, grade $3: \chi^{2}(4)=5.01$,

$p>.05$, grade $5: \chi^{2}(4)=2.36, p>.05$, and grade $8: \chi^{2}(4)=2.43, p>.05$; paternal education level across age groups: $\chi^{2}(4)=6.59$, grade $2: \chi^{2}(4)=1.72, p>.05$, grade 3 : $\chi^{2}(4)=6.17, p>.05$, grade $5: \chi^{2}(4)=0.83, p>.05$, and grade $\left.8: \chi^{2}(4)=6.44, p>.05\right)$. The ANOVA on HLE scores revealed no significant differences in function of language status, $F(1,144)=1.71, p>.05, \eta_{p}{ }^{2}=.03$, or age, $F(3,144)=1.79, p>.05, \eta_{p}{ }^{2}=.01$, and no interaction, $F(3,144)=1.08, p>.05, \eta_{p}{ }^{2}=.02$. For fluid intelligence, the effect of age was significant, $F(3,144)=31.83, p<.001, \eta_{p}{ }^{2}=.40$, but the effect of language status, $F(1,144)=2.73, p>.05, \eta_{p}{ }^{2}=.02$, and the interaction, $F(3,144)=0.77$, $p>.05, \eta_{p}{ }^{2}=.02$, were not. ${ }^{1}$

\section{Procedure}

Participants were tested individually in a quiet room of their school. The tasks 
were presented in a fixed order (K-BIT subscales, rapid automatic naming, n-back, reading span) over two separate experimental sessions, each one lasting 45 minutes. All computerized tasks were presented using E-Prime 2.0 software (Schneider, Eschman \& Zuccolotto, 2002), except for the rapid automatic naming task, which was run using DMDX (Forster \& Forster, 2003). Instructions read by a female native speaker of Spanish were recorded and presented over headphones at test. The instructions were repeated until the experimenter was able to confirm that the children had understood the task. Questionnaires regarding socioeconomic status, HLE and home language use were distributed at test for the children to have a parent or primary caregiver fill them out at home, and were recollected during the following test session. Teacher questionnaires including information regarding age, grade level, history of learning disorders, or other relevant diagnoses were completed by the class teachers during school breaks. Informed consent was obtained from parents or legal guardians prior to testing.

\section{Experimental tasks and variables}

[Insert Table 2]

\section{Vocabulary}

Expressive vocabulary knowledge was measured using the vocabulary subtest of the K-BIT (Kaufman \& Kaufman, 2000). We used raw scores to assess performance.

\section{Rapid automatic naming}

The Rapid Automatic Naming (RAN) task served as an approximation to verbal processing speed. In this task, participants are required to name six recurring letters and objects that are arranged in a random order as fast as possible. Serial naming reflects 
lexical retrieval and phonological lexical access (Wolf, 1986) and is less related to vocabulary knowledge than discreet naming, because only a very limited number of items per category (e. g., objects) are tested.

\section{Reading Span}

The Reading Span task was based on a Spanish version of Daneman and Carpenter's task (1980) that was adapted for children (García-Madruga et al., 2013). Participants are presented with a set of simple sentences and, upon completion of a set, are asked to recall the last word of all sentences. Sentence length was restricted to 8-9 words. The number of sentences presented within a set increased over consecutive blocks, starting from two and going up to six. Instructions were followed by a practice block. Correct and incorrect answers were recorded by the experimenter on an answer sheet. The final word of a set was to never be recalled first. The procedure yields a reading span score between 2 and 6 .

\section{N-back}

We used the same version of the n-back task as described by Pelegrina and colleagues (2015). The task consisted of four blocks, 0-back, 1-back, 2,-back and 3back (the 0-back block served for practice purposes only), and items to be updated were letters. Each level of the task (0-back, 1-back, etc.) was preceded by instructions, an example consisting of six trials, and a practice block. Practice blocks were repeated until a child reached a correct percentage of $60 \%$, and if on any task level this percentage was not reached, the procedure was ended. We calculated the sum of correct answers for each block (children who had not reached the cutoff level on a given block, and had therefore not proceeded any further on the task, received no points for the 
omitted blocks).

\section{Results}

All statistical analyses reported were two-tailed, and alpha set to .05.

\section{Language-based development}

Language-based development was assessed in terms of vocabulary and rapid naming. To measure vocabulary, we considered raw scores. For the RAN score, overall RTs from the object and letter categories were averaged to obtain a combined score. We carried out two separate ANOVAs with the factors age and language status.

Unsurprisingly, the main effect of age was significant for both vocabulary, $F(3,144)=$ 46.78, $p<.001, \eta_{p}{ }^{2}=.49$, and rapid naming, $F(3,144)=36.42, p<.001, \eta_{p}{ }^{2}=.43$. For vocabulary, there were no significant bilingual-versus-monolingual differences, $F$ (1, 144) $=1.32, p>.05, \eta_{p}{ }^{2}<.01$, but monolinguals were significantly faster than bilinguals in rapid naming, $F(1,144)=5.32, p<.05, \eta_{p}{ }^{2}=.04$. The interaction between age and language status was not significant for either vocabulary, $F(3,144)=1.20$, $p>.05, \eta_{p}{ }^{2}=.02$, or RAN, $F(3,144)=1.0, p>.05, \eta_{p}{ }^{2}=.02$. There were significant linear trends for the effect of age on both variables, vocabulary, $F(1,64)=197.08, p$ $<.001, \eta_{p}{ }^{2}=.76$, and RAN, $F(1,64)=120.33, p<.001, \eta_{p}{ }^{2}=.65$. Figure 1 illustrates language-based development over age.

Given that the developmental course of the linguistic abilities underlying rapid naming appeared to differ between monolingual and bilingual children, we carried out planned contrasts for consecutive age levels within each group. Effects of age were significant for both bilinguals, $F(3,72)=18.27, p<.001, \eta_{p}{ }^{2}=.43$, and monolinguals, $F$ $(3,72)=19.23, p<.001, \eta_{p}{ }^{2}=.45$. Bilinguals' performance increased only marginally 
between the $2^{\text {nd }}$ and $3^{\text {rd }}$ grade, $F(1,38)=3.57, p=.07, \eta_{p}{ }^{2}=.09$, whereas monolinguals showed a large, significant increase, $F(1,38)=13.35, p=.001, \eta_{p}{ }^{2}=.26$. On the other hand, bilinguals' performance showed a significant increase between grades 3 and 5, $F$ $(1,40)=5.2, p=.03, \eta_{p}{ }^{2}=.12$, but monolinguals' performance did not, $F(1,40)=1.75$, $p>.05, \eta_{p}{ }^{2}=.04$. Both groups improved significantly between grades 5 and $8, F_{s}(1,34)$ $\geq 8.3, p \leq .007, \eta_{p}{ }^{2} \geq .20$. The difference between bilinguals and monolinguals reached significance in grade $3, F(1,40)=4.60, p=.04, \eta_{p}{ }^{2}=.10($ all other $F \mathrm{~s} \leq 2.06, p \mathrm{~s}>.05)$.

[Insert Figure 1]

\section{Working Memory}

Two separate ANOVAs with the factors age and language status were conducted, with scores for correctly recalled items on the n-back by block and reading span scores as dependent variables. For the n-back task, block was included as an additional variable. For age-related changes in WM performance, see Figures 2 (n-back) and 3 (reading span).

\section{N-back}

The main effect of block, $F^{2}(1.64,236.39)=181.71, p<.001, \eta_{p}{ }^{2}=.56$, and its interaction with age, $F(4.93,236.39)=2.98, p=.01, \eta_{p}{ }^{2}=.06$, were significant, indicating stronger age effects as the task increased in difficulty (see figure 2, $p$ s $<.001$, for all linear trends). However, block did not interact with any other variable $(F \mathrm{~s}$ $\left.\leq .2 .22, p \mathrm{~s}>.05, \eta_{p} \mathrm{~s}^{2} \leq .02\right)$. We further observed main effects of age, $F(3,144)=$ $15.32, p<.001, \eta_{p}{ }^{2}=.24$, with older children outperforming younger ones as confirmed by a linear trend, $F(1,64)=38.87, p<.001, \eta_{p}{ }^{2}=.38$, and language status, $F(1,144)=$ $5.85, p=.02, \eta_{p}{ }^{2}=.04$, with bilinguals outperforming monolinguals. 


\section{[Insert Figure 2]}

Although the interaction between age and language status was not significant, $F$ $(3,144)=1.92, p>.05, \eta_{p}{ }^{2}=.04$, additional analyses ${ }^{3}$ and visual inspection of the group means suggested that the effect of language status was age-dependent. To better understand these developmental patterns, we conducted a series of follow-up ANOVAs by language status and age. Given that block did not interact with language status or its interactions, for the sake of simplicity, n-back scores were collapsed across block for these analyses.

Effects of age on n-back scores were significant for both bilingual, $F(3,72)=$ $5.49, p=.002, \eta_{p}{ }^{2}=.19$, and monolingual children, $F(3,72)=11.31, p<.001, \eta_{p}{ }^{2}=.32$. According to planned contrasts for consecutive age levels, bilinguals' performance increased significantly from the $5^{\text {th }}$ to the $8^{\text {th }}$ grade, $F(1,34)=11.24, p=.002, \eta_{p}{ }^{2}=.25$. Monolinguals showed a significant increase between grades 3 and $5, F(1,40)=12.73$, $p=.001, \eta_{p}{ }^{2}=.24$, and a marginally significant increase between grades 5 and $8, F(1$, $34)=3.97, p=.05, \eta_{p}{ }^{2}=.11$. None of the other contrasts were significant, all $F \mathrm{~s} \leq 0.11$,

$p \mathrm{~s}>.05, \eta_{p}{ }^{2} \mathrm{~s}<.01$. Separate ANOVAs by age revealed that the effect of language status was marginally significant in grade $2, F(1,36)=3.87, p=.06, \eta_{p}{ }^{2}=.10$, and significant in grade $3, F(1,40)=6.92, p=.01$, but not in grade 5 or $8, F \mathrm{~s} \leq 0.64, p>.05, \eta_{p}{ }^{2} \leq .02$. That is, a bilingual advantage was observed before, but not after monolinguals showed a developmental leap in task performance.

\section{Reading Span}

Reading span scores (see task description) were also subject to a significant effect of age, $F(3,144)=11.94, p<.001, \eta_{p}{ }^{2}=.20$, with older children performing 
better than younger ones, as indicated by a significant linear trend, $F(1,64)=32.03, p$ $<.001, \eta_{p}{ }^{2}=.33$. Bilinguals and monolinguals performed at the same overall level, $F(1$, $144)=.01, p>.05, \eta_{p}^{2}<.01$, but there was a significant interaction between age and language status, $F(3,144)=2.92, p=.04, \eta_{p}{ }^{2}=.06^{4}$.

\section{[Insert Figure 3]}

Follow-up ANOVAs by language status showed significant age effects for bilinguals, $F(1,72)=11.06, p<.001, \eta_{p}{ }^{2}=.32$, and monolinguals, $F(1,72)=3.34, p$ $=.02, \eta_{p}{ }^{2}=.12$. The developmental course for this task differed for both groups as in monolinguals, a marginally significant improvement was observed between grades 2 and $3, F(1,38)=3.59, p=.07, \eta_{p}{ }^{2}=.09$, while bilinguals' performance increased at a later stage, between grades 3 and $5, F(1,40)=14.26, p=.001, \eta_{p}{ }^{2}=.26$. None of the other planned contrasts between consecutive grade levels were significant, $F \mathrm{~s} \leq 2.20$, $p>.05, \eta_{p}{ }^{2}<.06$. ANOVAs by age showed marginal effects of language status in $3^{\text {rd }}$ grade, $F(1,40)=3.76, p=.06, \eta_{p}{ }^{2}=.09$, where monolinguals reached higher scores, and $5^{\text {th }}$ grade, $F(1,40)=3.02, p=.09, \eta_{p}^{2}=.07$, where bilinguals performed better. Thus, the outcome of the between-group comparison changed after bilinguals showed an agerelated increase. No significant between-group differences were observed for $2^{\text {nd }}$ graders, $F(1,36)=.86, p>.05, \eta_{p}{ }^{2}=.02$, or $8^{\text {th }}$ graders, $F(1,28)=.65, p>.05, \eta_{p}{ }^{2}$ $=.02$.

\section{Correlations}

In order to corroborate the assumption that reading span is more related to verbal processing than the n-back task, we calculated partial correlations between WM tasks and rapid naming (where bilinguals had scored lower than monolinguals) for the entire 
sample while controlling for the effect of age. Reading span proved to be significantly correlated with RAN scores, $r=-.17, p=.04$, but $n$-back scores did not $(r=-.02$, $p>.05)$. The relationship between $\mathrm{n}$-back and reading span scores did not reach significance either $(r=.01, p>.05)$.

\section{Discussion}

The aim of this research was to explore the development of WM performance in school age and assess whether emergent bilingual children immersed in an L2 at school show developmental modulations. To that end, we compared children aged seven through 14 who were enrolled in the second, third, fifth, or eighth grade of an L2 immersion school to monolinguals of the same age on two measures of WM. Research into the cognitive consequences of L2 immersion education is still scarce, although this type of schooling has been gaining popularity. Our goal was to build on previous findings (e.g. Bialystok \& Barac, 2012, Nicolay \& Poncelet, 2013) to fill this gap. Although the present study was cross-sectional as most research on bilingualism and cognitive control, we aimed to ensure that both groups be as similar as possible in factors other than language status, including age, gender, SES, fluid intelligence and home literacy environment. Main effects of age for measures of linguistic and WM performance confirm that the selected tasks are sensitive measures of individual differences in the cognitive development of children this age in the respective domains.

Our parting hypothesis was that emergent bilingualism - the onset of multiple language use and acquisition - is associated with both cognitive advantages (i.e., enhanced cognitive control) and deficits (i.e., delayed or impaired language skills), and that both are relevant for WM performance (see also Bialystok, 2009). We thus predicted that i) emergent bilinguals might lag behind their monolingual age-peers on 
language tasks in the L1, and that ii) emergent bilinguals would excel on a WM task that places high demands on executive control and is linguistically less demanding (n-back task). Finally, we predicted that if both linguistic costs and executive advantages occur in emerging bilinguals, the two groups might show similar performance on a WM task that places equal demands on executive and non-executive linguistic processes (i.e., reading span).

Regarding verbal processing in the L1, we found that emergent bilingual children were significantly slower than their monolingual counterparts, as evidenced by reaction times on the rapid automatic naming task, although it should be noted that this difference was only significant for third graders. This finding stands in line with previous research showing relatively slower lexical access in bilinguals (e.g., Ivanova \& Costa, 2008, Yan \& Nicoladis, 2009), especially slowed L1 processing as a consequence of L2 immersion in sequential bilingualism (Linck et al., 2009). To our knowledge, this research is the first one to extend these findings to children immersed in the L2 at school. On the other hand, both groups showed similar levels of vocabulary knowledge, suggesting a dissociation of knowledge-based and processing-based aspects of language development. A similar pattern was observed by Yan and Nicoladis (2009), who report greater difficulties with lexical access, combined with monolingual-like vocabulary scores in school-aged (balanced) bilinguals. Within-language vocabulary scores of bilingual children depend on the exposure time to each language (Genesee \& Nicoladis, 2007), while the difficulty in lexical access and retrieval can be explained as being due to the added cognitive load from the second language during bilinguals' language processing (Yan \& Nicoladis, 2009).

In regards to WM updating, we observed a bilingual advantage in the younger 
age groups (grades 2 and 3), although no between-group differences were observed for older children (grades 5 and 8). Although our version of the n-back task uses verbal content, it is a relatively pure measure of executive WM updating. The finding for younger emergent bilinguals is thus consistent with previous research showing an executive advantage in L2 immersion students (e.g., Bialystok \& Barac, 2012, Nicolay \& Poncelet, 2013), as well as research with early bilinguals using WM tasks that were high in executive load (Carlson \& Meltzoff, 2008, Morales et al., 2013). This finding suggests that emergent bilingualism may alter the developmental trajectories of WMrelated processes, rather than ultimate achievement as such (we will come back to this point). Previous research with immersion students has often been limited to younger children within the first three years of L2 immersion (e.g., Nicolay \& Poncelet, 2013, 2015, Poarch \& van Hell, 2012), so it is unclear to what extent the lack of betweengroup differences for older immersion students is consistent or inconsistent with these studies.

Reading span requires executive control, but at the same time, relies more heavily on linguistic processing. In line with some previous research (e.g. Blom, Küntay, Messer, Verhagen, \& Leseman, 2014), we postulated that putative bilingual costs and benefits would cancel each other out, and predicted no between-group differences for this task. Memory falls unto a middle ground in terms of bilingual costs and benefits: as executive and linguistic processes both affect performance, the relative outcome compared to monolinguals depends to the extent to which a task draws on either (see Bialystok, 2009). Our results indicate the greatest age-related outcome differences for this task. In particular, younger bilinguals (grade 3) who outperformed their monolingual age-peers on the n-back task, showed a marginal disadvantage on the reading span task. It seems that the linguistic deficit in bilingual children at this age 
level showed through on the reading span task as it requires a relatively high level of linguistic functioning. This dissociation suggests that is important to consider the specific task content, that is, the relative contribution of executive and non-executive components, to the outcome when comparing bilinguals and monolinguals on WM paradigms. A recent study suggests that linguistic deficits can affect bilinguals' performance on WM negatively on tasks tapping both central executive and domaingeneral verbal components, although contrary to our research, verbal WM was tested in bilinguals' less dominant L2 (Blom et al., 2014).

As mentioned above, it is important to note that between-group differences emerged at certain grade levels. While the interaction with age was only significant for reading span, further comparisons revealed that the language effects for the n-back task and rapid automatic naming were also clearly driven by differences in younger age groups. Thus, our data suggest that L2 immersion may boost or delay WM processes at earlier developmental stages, but all children eventually reach a similar level of performance (see Morales et al., 2013, for a similar interpretation). A comparison of age effects within-group confirmed that immersion students in grades 2 and 3 performed the n-back task at a level that monolinguals did not reach until the $5^{\text {th }}$ grade. The pattern for the reading span task was reversed, as monolinguals showed increased performance between grades 2 and 3 and bilinguals lagged behind until later on (grade 5). Similarly, monolinguals' naming performance showed a large and reliable improvement between grades 2 and 3, while the age-related reduction in bilinguals was significant later on, between grades 3 and 5.Together, data from these two tasks suggest that linguistic processing abilities develop earlier in monolinguals whereas they develop more progressively in emergent bilinguals. Both groups also showed increased performance in rapid naming between the $5^{\text {th }}$ and $8^{\text {th }}$ grade, suggesting that speed and fluency of 
lexical access continue to increase substantially into adolescence but at this stage, development in monolingual children and immersion students proceeds similarly. Again, this suggests that rather than affecting ultimate attainment, becoming immersed in a second language can alter the developmental course of language-based abilities. The lack of between-group differences in the higher grades may be surprising, as one might expect that with longer exposure to a bilingual immersion environment, cognitive consequences in terms of measurable effects should increase. On the other hand, it is plausible that younger bilinguals who are still new to interacting in their less dominant L2 experience the largest transfer effects, as cross-language interference and executive control demands should be particularly high at this stage. Cognitive consequences of bilingualism tend to be most easily detectable in developmental stages of less-thanoptimal executive performance, that is, childhood and old age (Craik \& Bialystok, 2006) and training effects in the context of executive function generally tend to be larger at earlier intervention and developmental stages (Diamond \& Lee, 2011).

\section{Conclusion}

In conclusion, the present research offers several contributions to understanding WM development and bilingualism. We report one of the first studies to investigate the cognitive consequences of emergent bilingualism through L2 immersion at school and extend some of the findings from early bilinguals to this group. In regards to the nature of WM development, our data suggest that WM is more susceptible to modulatory effects at earlier stages. Thirdly, we show that WM tasks that differ in the relative contribution of sub-components may lead to different outcomes of a between-group comparison. WM is a multi-component construct (e.g., Baddeley \& Hitch, 1974, Gathercole et al., 2004,), and our findings highlight the importance of considering the 
specific task content, and ideally, to use several alternative tasks that allow one to estimate differences at the level of sub-components. The important question remains whether the specific modulations have practical consequences. Further study is needed in order to determine whether any of these effects show transfer into other cognitive abilities and domains. This should prove a fruitful field for future research. 


\section{Footnotes}

${ }^{1}$ Although there were no differences between bilingual and monolingual children in any of the control variables, we additionally compared the two groups within each age group. Overall there were no differences due to language status in these control variables in most comparisons $(p s>.05)$ except for fluid intelligence in the oldest age group $F(1,28)=28.44, p<.001, \eta_{p}{ }^{2}=.50$, and for HLE in the second age group, $F(1$, $40)=4.66, p=.04, \eta_{p}{ }^{2}=.10$. To ensure these differences did not influence the results, we performed parallel ANCOVAs with HLE and fluid intelligence as covariates for all analyses on N-back, Reading span, Vocabulary, and RAN scores; the outcome in regards to all data patterns was the same as for the ANOVAs reported in the upcoming results section.

${ }^{2}$ Degrees of freedom for within-subject effects were corrected using the GreenhouseGeisser correction.

${ }^{3}$ ANOVAs for combined age groups (younger children in grades 2 and 3 vs. older children in grades 5 and 8) confirm main effects of age, $F(1,148)=30.21, p<.001$, $\eta_{p}{ }^{2}=.17$, and language status, $F(1,148)=4.75, p=.03, \eta_{p}{ }^{2}=.03$, as well as a significant interaction, $F(1,148)=4.42, p=.03, \eta_{p}{ }^{2}=.03$. Comparing the effect of language status within the two broader age groups revealed that younger bilingual children, $F(1,78)=$ 9.72, $p<.01, \eta_{p}{ }^{2}=.11$, but not in older ones, $F(1,78)=.003, p>.05, \eta_{p}{ }^{2}<.05$, outperformed monolinguals on the n-back task.

${ }^{4}$ ANOVAs with combined age groups confirmed the effect of age, $F(1,148)=29.33, p$ $<.001, \eta_{p}{ }^{2}=.17$ and the significant interaction between age and language status, $F(1$, $148)=7.44, p=.007, \eta_{p}{ }^{2}=.05$. The effect of language status remained non-significant, $F(1,148)=0.01, p>.05, \eta_{p}{ }^{2}<.01$. Younger children had better reading span scores 
than their bilingual age peers, $F(1,78)=4.48, p=.04, \eta_{p}{ }^{2}=.05$, while in older children, there was a tendency towards a bilingual advantage, $F(1,78)=3.08, p=.08, \eta_{p}{ }^{2}=.04$. 
References

Adesope, O., Lavin, T., Thompson, T., \& Ungerleider, C. (2010). A systematic review and meta-analysis of the cognitive correlates of bilingualism. Review of Educational Research, 80, 207-245. doi: 10.3102/0034654310368803.

Antón, E., Duñabeitia, J. A., Estévez, A., Hernández, J. A., Castillo, A., Fuentes, L. J., ... \& Carreiras, M. (2014). Is there a bilingual advantage in the ANT task? Evidence from children. Frontiers in psychology, 5. doi: 10.3389/fpsyg.2014.00398.

Baddeley, A. D., \& Hitch, G. J. (1974). Working Memory. In: Bower, G. H. (Eds.). The Psychology of Learning and Motivation: Advances in Research and Theory (Volume 8) (pp. 47-89). New York: Academic Press.

Bayliss, D. M., Jarrold, C., Gunn, D. M., \& Baddeley, A. D. (2003). The complexities of complex span: Explaining individual differences in working memory in children and adults. Journal of Experimental Psychology: General, 132, 71-92. doi: 10.103 7/0096-3445.132.1.71.

Bialystok, E. (2001). Bilingualism in Development: Language, Literacy, and Cognition. New York: Cambridge University Press.

Bialystok, E. (2009). Bilingualism: The good, the bad, and the indifferent. Bilingualism: Language and Cognition, 12, 3-11. doi: 10.1017/S1366728908003477.

Bialystok, E., \& Barac, R. (2012). Emerging bilingualism: Dissociating advantages for metalinguistic awareness and executive control. Cognition, 22, 67-73. doi: 10.1 016/j.cognition.2011.08.003. 
Bialystok, E., \& Feng, X. (2009). Language proficiency and executive control in proactive interference: Evidence from monolingual and bilingual children and adults. Brain and Language, 109, 93-100. doi: 10.1016/j.bandl.2008.09.001.

Bialystok, E., \& Luk, G. (2012). Receptive vocabulary differences in monolingual and bilingual adults. Bilingualism: Language and Cognition, 15, 397-401. doi: 10.1 017/S136672891100040X.

Bialystok, E., Luk, G., Peets, K. F., \& Yang, S. (2010). Receptive vocabulary differences in monolingual and bilingual children. Bilingualism: Language and Cognition, 13, 525-531. doi: 10.1017/S1366728909990423.

Blom, E., Küntay, A. C., Messer, M., Verhagen, J., \& Leseman, P. (2014). The benefits of being bilingual: Working memory in bilingual Turkish-Dutch children. Journal of Experimental Child Psychology, 128, 105-119. doi: 10.1016/ j.jecp.2014.06.007.

Bonifacci, P., Giombini, L., Bellochi, S., \& Contento, S. (2011). Speed of processing, anticipation, inhibition and working memory in bilinguals. Developmental Science, 14, 256-269. doi: 10.1111/j.1467-7687.2010.00974.x.

Carlson, S. M., \& Meltzoff, A. N. (2008). Bilingual experience and executive functioning in young children. Developmental Science, 11, 282-298. doi: 10.11 11/j.1467-7687.2008.00675.x.

Carretti, B., Borella, E., Cornoldi, C., \& de Beni, R. (2009). Role of working memory in explaining the performance of individuals with specific reading comprehension difficulties: A meta-analysis. Learning and Individual Differences, 19, 246-251. 
doi: 10.1016/j.lindif.2008.10.002.

Cohen, J. D., Perlstein, W. M., Braver, T. S., Nystrom, L. E., Noll, D. C., Jonides, J., \& Smith, E. E. (1997). Temporal dynamics of brain activation during a working memory task. Nature, 386, 604-608. doi: 10.1038/386604a0.

Craik, F. I. M., \& Bialystok, E. (2006). Cognition through the lifespan: Mechanisms of change. Trends in Cognitive Sciences, 10, 131-138. doi: 10.1016/j.tics.2006.01. 007.

Daneman, M., \& Carpenter, P.A. (1980). Individual differences in working memory and reading. Journal of Verbal Learning and Verbal Behavior, 19, 450-466. doi: $10.1016 / 50022-5371(80) 90312-6$.

Diamond, A., \& Lee, K. (2011). Interventions shown to aid executive function development in children 4 to 12 years old. Science, 333, 959-964. doi: 10.1126/science. 1204529 .

Duñabeitia, A., Hernández, J. A., Antón, E., Macizo, P., Estévez, A., Fuentes, L. J., \& Carreiras, M. (2014). The inhibitory advantage in bilingual children revisited: Myth or reality? Experimental Psychology, 61, 234-51. doi: 10.1027/16183169/a000243.

Engel de Abreu, P. (2011). Working memory in multilingual children: Is there a bilingual effect? Memory, 19, 529-537. doi: 10.1080/09658211.2011.590504.

Engle, R. W., Tuholski, S. W., Laughlin, J. E., \& Conway, A. R. A. (1999). Working memory, short-term memory, and general fluid intelligence: A latent variable 
approach. Journal of Experimental Psychology: General, 128, 309-331. doi: 10.1016/s0160-2896(01)00096-4.

Forster, K. I., \& Forster, J. C. (2003). DMDX: A windows display program with millisecond accuracy. Behavior Research Methods, Instruments, \& Computers, 35, 116-124. doi: 10.3758/bf03195503.

Gaillard, V., Barrouillet, P., Jarrold, C., \& Camos, V. (2011). Developmental differences in working memory: Where do they come from? Journal of Experimental Child Psychology, 110, 469-479. doi: 10.1016/j.jecp.2011.05.004.

García-Madruga, J., Elosúa, M., R., Gil, L., Gómez-Veiga, I., Vila, J. Ó., Orjales, I., Contreras, A., Rodríguez, R., Melero, M. Á., \& Duque, G. (2013). Reading Comprehension and Working Memory’s Executive Processes: An Intervention Study in Primary School Students. Reading Research Quarterly, 48, 155-174. doi: $10.1002 /$ rrq. 44 .

Gathercole, S. E., Pickering, S. J., Ambridge, B., \& Wearing, H. (2004). The structure of working memory from 4 to 15 years of age. Developmental Psychology, 40, 177190. doi: $10.1037 / 0012-1649.40 .2 .177$.

Gathercole, S. E., Pickering, S. J., Knight, C., \& Stegmann, Z. (2004). Working memory skills and educational attainment: Evidence from national curriculum assessments at 7 and 14 years of age. Applied Cognitive Psychology, 18, 1-16. doi: 10.1002/acp.934.

Genesee, F., \& Nicoladis, E. (2007). Bilingual first language acquisition. In Hoff, E., \& Shatz, M. (Eds.). Handbook of Language Development. Oxford: Blackwell. 
Hilchey, M. D., \& Klein, R. (2011). Are there bilingual advantages on nonlinguistic interference tasks? Implications for the plasticity of executive control processes. Psychonomic Bulletin \& Review, 18, 625-658. doi: 10.3758/s13423-011-0116-7.

Ivanova, I., \& Costa, A. (2008). Does bilingualism hamper lexical access in speech production? Acta Psychologica, 127, 277-288. doi: 10.1016/j.actpsy.2007.06. 003.

Kaufman, A.S., \& Kaufman, N.L. (2000). K-BIT, test breve de inteligencia de Kaufman [K-BIT, the brief test of intelligence by Kaufman]. Spanish adaptation by Cordero Pando, A., \& Calonge Romano, I. New York: PsychCorp.

Linck, J. A., Kroll, J. F., \& Sunderman, G. (2009). Losing access to the native language while immersed in a second language: Evidence for the role of inhibition in second-language learning. Psychological Science, 20, 1507-1515. doi: 10.1111/j.1467-9280.2009.02480.x

Luk, G., Green, D. W., Abutalebi, J., \& Grady, C. (2012). Cognitive control for language switching in bilinguals: A quantitative meta-analysis of functional neuroimaging studies. Language and Cognitive Processes, 27, 1479-1488. doi: 10.1080/01690965.2011.613209.

Luo, L., Craik, F. I. M., Moreno, S., \& Bialystok, E. (2012). Bilingualism interacts with domain in a working memory task: Evidence from aging. Psychology and Aging, 28, 28-34. doi: 10.1037/a0030875.

McCabe, D. P., Roediger, H. L., McDaniel, M. A., Balota, D. A., \& Hambrick, D. Z. (2010). The relationship between working memory capacity and executive 
functioning: Evidence for a common executive attention construct.

Neuropsychology, 24, 222-243. doi: 10.1037/a0017619.

Miyake, A., Friedman, N. P., Emerson, M. J., Witzki, A. H., \& Howerter, A. (2000). The unity and diversity of executive functions and their contributions to complex "frontal lobe" tasks: A latent variable analysis. Cognitive Psychology, 41, 49100. doi: 10.1006/cogp.1999.0734.

Morales, J., Calvo, A., \& Bialystok, E. (2013). Working memory development in monolingual and bilingual children. Journal of Experimental Child Psychology, 114, 187-202. doi: 10.1016/j.jecp.2012.09.002.

Namazi, M., \& Thorardottir, E. (2010). A working memory, not bilingual advantage, in controlled attention. International Journal of Bilingual Education and Bilingualism, 13, 597-616. doi: 10.1080/13670050.2010.488288.

Nicolay, A.-C., \& Poncelet, M. (2013). Cognitive advantage in children enrolled in a second-language immersion elementary school program for three years. Bilingualism: Language and Cognition, 16, 597-607. doi: 10.1017/s136672891 2000375.

Nicolay, A. C., \& Poncelet, M. (2015). Cognitive benefits in children enrolled in an early bilingual immersion school: A follow up study. Bilingualism: Language and Cognition, 18, 789-795. doi: 10.1017/S1366728914000868.

Paap, K. R., \& Greenberg, Z. I. (2013). There is no coherent evidence for a bilingual advantage in executive processing. Cognitive Psychology, 66, 232-258. doi: 10.1016/j.cogpsych.2012.12.002. 
Pelegrina, S., Lechuga, M. T., García-Madruga, J. A., Elosúa, M. R., Macizo, P., Carreiras, M., ... \& Bajo, M. T. (2015). Normative data on the n-back task for children and young adolescents. Frontiers in Psychology, 6. doi: 10.3398/fpsyg.2015.01444

Poarch, G. J., \& van Hell, J. G. (2012). Executive functions and inhibitory control in multilingual children: Evidence from second-language learners, bilinguals, and trilinguals. Journal of Experimental Child Psychology, 113, 535-551. doi: 10.1016/j.jecp.2012.06.013.

Poulin-Dubois, D., Bialystok, E., Blaye, A., Polonia, A., \& Yott, J. (2010). Lexical access and vocabulary development in very young bilinguals. International Journal of Bilingualism, 17, 57-70. doi: 10.1177/1367006911431198.

Raghubar, K. P., Barnes, M. A., \& Hecht, S. A. (2010). Working memory and mathematics: A review of developmental, individual difference, and cognitive approaches. Learning and Individual Differences, 20, 110-122. doi: 10.1016/ j.lindif.2009.10.005.

Schmiedek, F. \& Hildebrandt, A., Lövdén, M., Wilhelm, O. \& Lindenberger, U. (2009). Complex span versus updating tasks of Working Memory: the gap is not that deep. Journal of Experimental Psychology: Learning, Memory and Cognition, 35, 1089-1096. doi: 10.1037/a0015730

Schneider, W., Eschman, A., \& Zuccolotto, A. (2002). E-Prime User's Guide. Pittsburgh: Psychology Software Tools Inc. 
Thierry, G., \& Wu, Y. G. (2007). Brain potentials reveal unconscious translation during foreign-language comprehension. Proceedings of the National Academy of Sciences, 104, 12530-12535. doi: 10.1073/pnas.0609927104.

Van Hell, J. G., \& Dijkstra, T. (2002). Foreign language knowledge can influence native language performance in exclusively native contexts. Psychonomic Bulletin \& Review, 9, 780-789. doi: 10.3758/bf03196335.

Wolf, M. (1986). Rapid alternating stimulus naming in the developmental dyslexias. Brain and Language, 27, 360-379. doi: 10.1016/0093-934X(86)90025-8.

Yan, S., \& Nicoladis, E. (2009). Finding le mot juste: Differences between bilingual and monolingual children's lexical access in comprehension and production. Bilingualism, Language and Cognition, 12, 323-335. doi: $10.1017 / \mathrm{s} 1366728909990101$. 


\section{Captions for Figures}

Figure 1. (a) Mean vocabulary expressed as raw scores and (b) rapid automatic naming (RAN) in seconds, for monolingual (ML) versus bilingual (BL) children divided by age. Error bars represent the standard error of the mean.

Figure 2. N-back scores (overall sum of correct responses) for monolingual (ML) versus bilingual (BL) children, divided by age for a) the 1-back, b) the 2-back, and c) the 3back block. Error bars represent the standard error of the mean.

Figure 3. Mean reading span for monolingual (ML) versus Bilingual (BL) children, divided by age. Error bars represent the standard error of the mean. 
Table 1

Socioeconomic status and fluid intelligence

\begin{tabular}{|c|c|c|c|c|c|c|c|c|}
\hline \multirow[b]{2}{*}{ Grade } & \multicolumn{2}{|c|}{ Maternal Education } & \multicolumn{2}{|c|}{ Paternal Education } & \multicolumn{2}{|c|}{ Home Literacy Environment } & \multicolumn{2}{|c|}{ Fluid Intelligence } \\
\hline & Bilinguals & Monolinguals & Bilinguals & Monolinguals & Bilinguals & Monolinguals & Bilinguals & Monolinguals \\
\hline 2 nd & 5 & 5 & 5 & 5 & $2.11(0.03)$ & $2.05(0.04)$ & $24.42(0.94)$ & $24.16(1.20)$ \\
\hline $3 \mathrm{rd}$ & 5 & 5 & 5 & 5 & $2.28(0.04)$ & $2.02(0.03)$ & $26.96(1.04)$ & $26.38(0.78)$ \\
\hline 5 th & 5 & 5 & 5 & 4 & $2.20(0.03)$ & $2.27(0.03)$ & $34.41(0.84)$ & $32.90(3.03)$ \\
\hline 8 th & 5 & 5 & 5 & 5 & $2.08(0.04)$ & $2.02(0.03)$ & $39.53(0.68)$ & $35.00(0.51)$ \\
\hline TOTAL & 5 & 5 & 5 & 5 & $2.18(0.05)$ & $2.09(0.03)$ & $30.86(0.80)$ & $29.33(1.03)$ \\
\hline
\end{tabular}

Note. Socioeconomic status and general cognitive level of monolingual as compared to bilingual children by age. Group medians for maternal and paternal education are based on a 5-point scale with (5) - College +, (4) - Vocational Training, (3) - High School, (2)

- Secondary/Middle School, (1) - Elementary School level degree. Values for home literacy environment express group means for the frequency of literacy-related activities at home, with (0) - Never, (1) - Sometimes, (3) - Almost always, (4) - Always. Parenthesized values represent the respective standard errors of the mean. 
Table 2

Working memory and linguistic development

\begin{tabular}{|c|c|c|c|c|c|c|}
\hline \multirow[b]{2}{*}{ Grade } & Bilinguals & Monolinguals & Bilinguals & Monolinguals & Bilinguals & Monolinguals \\
\hline & \multicolumn{2}{|c|}{ 1-back } & \multicolumn{2}{|c|}{ 2-back } & \multicolumn{2}{|c|}{ 3-back } \\
\hline 2nd & $30.21(1.36)$ & $26.11(1.68)$ & $25.16(1.26)$ & $17.53(2.89)$ & $14.53(3.08)$ & $9.95(2.91)$ \\
\hline $3 \mathrm{rd}$ & $30.48(1.64)$ & $26.29(1.49)$ & $24.71(2.15)$ & $16.29(1.85)$ & $16.29(2.51)$ & $6.71(2.13)$ \\
\hline 5 th & $30.43(1.42)$ & $33.29(1.22)$ & $25.86(1.85)$ & $17.86(1.90)$ & $17.86(3.13)$ & $17.57(3.28)$ \\
\hline 8th & $36.00(0.60)$ & $35.67(0.84)$ & $32.93(1.05)$ & $29.07(2.54)$ & $29.07(1.18)$ & $25.53(2.87)$ \\
\hline TOTAL & $31.49(0.73)$ & $30.03(0.83)$ & $26.76(0.93)$ & $23.33(1.28)$ & $18.80(1.47)$ & $14.24(1.61)$ \\
\hline Grade & \multicolumn{2}{|c|}{ Reading Span } & \multicolumn{2}{|c|}{ Vocabulary } & \multicolumn{2}{|c|}{ Rapid Automatic Naming } \\
\hline 2nd & $2.72(0.12)$ & $2.88(0.12)$ & $40.05(1.49)$ & $41.16(1.10)$ & $32.80(1.08)$ & $31.78(1.39)$ \\
\hline $3 \mathrm{rd}$ & $2.83(0.17)$ & $3.35(0.21)$ & $45.67(1.12)$ & $45.05(1.05)$ & $29.28(1.47)$ & $25.30(1.13)$ \\
\hline 5 th & $3.69(0.16)$ & $3.32(0.14)$ & $52.54(2.70)$ & $51.96(1.47)$ & $25.27(0.96)$ & $23.48(0.79)$ \\
\hline 8th & $3.93(0.28)$ & $3.66(0.18)$ & $61.47(1.33)$ & $56.40(1.15)$ & $20.91(0.62)$ & $20.46(0.55)$ \\
\hline TOTAL & $3.26(0.11)$ & $3.29(0.09)$ & $49.28(1.26)$ & $48.22(0.89)$ & $27.40(0.93)$ & $25.46(0.74)$ \\
\hline
\end{tabular}

Note. Mean scores and standard errors (parenthesized) for WM and linguistic tasks in monolingual compared to bilingual children, divided by age. 